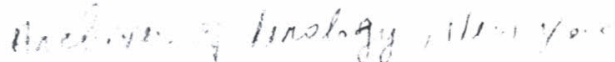

Arch Virol (2003) 148: 281-295

DOI $10.1007 / \mathrm{s} 00705-002-0917-0$

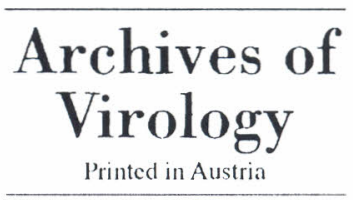

\title{
Distribution and genetic diversity of tomato-infecting begomoviruses in Brazil*
}

\author{
S. G. Ribeiro ${ }^{1}$, L. P. Ambrozevícius ${ }^{2}$, A. C. Ávila ${ }^{3}$, I. C. Bezerra ${ }^{3}$, \\ R. F. Calegario ${ }^{2}$, J. J. Fernandes ${ }^{2}$, M. F. Lima ${ }^{4}$, R. N. de Mello ${ }^{2}$, \\ H. Rocha ${ }^{3}$, and F. M. Zerbini \\ 'EMBRAPA Recursos Genéticos e Biotecnologia, \\ Parque Estação Biológica, Brasília, Brazil \\ ${ }^{2}$ Departamento de Fitopatologia/BIOAGRO, \\ Universidade Federal de Viçosa, Viçosa, Brazil \\ ${ }^{3}$ EMBRAPA Hortaliças, Brasília, Brazil \\ ${ }^{4}$ EMBRAPA Semi-Árido, Petrolina, Brazil
}

Received December 21, 2001; accepted September 1, 2002

Published online November 8, 2002 (C) Springer-Verlag 2002

\begin{abstract}
Summary. Tomato-infecting begomoviruses have been reported throughout Brazil since the introduction of the B biotype of Bemisia tabaci. Here, we report a large scale survey on the distribution and genetic diversity of tomato-infecting begomoviruses. Tomato samples with typical begomovirus symptoms were collected in seven different states, comprising the major tomato growing areas of the country. Viruses were detected by polymerase chain reaction (PCR) using universal primers for the genus Begomovirus. PCR-amplified fragments were cloned and sequenced. Based on sequence comparisons and phylogenetic analyses, at least seven previously undescribed species of begomoviruses were found. Four of the new viruses were found exclusively in the Southeastern states, two exclusively in the Northeastern states, and one was found in both regions. Sequence comparisons reveal strong evidence of recombination among the Brazilian begomoviruses. Together, the results indicate the existence of a high degree of pre-existing genetic diversity among tomato-infecting begomoviruses in Brazil and suggest that these viruses have emerged after being transferred from natural hosts to tomatoes, due to the introduction into Brazil of a novel polyfagous biotype of the whitefly vector.
\end{abstract}

${ }^{*}$ The sequences reported in this paper have been deposited into the GenBank under the accession numbers AY049205 to AY049227.

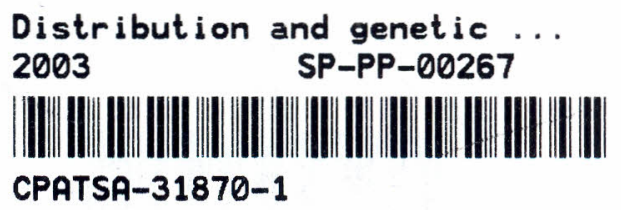




\section{Introduction}

Geminiviruses are small, single-stranded DNA plant viruses with a unique particle morphology of twinned incomplete icosahedra. The family Geminiviridae is divided into four genera (Mastrevirus, Curtovirus, Topocuvirus and Begomovirus), based on genome structure, type of insect vector and host range [17, 23]. Begomoviruses are transmitted by whiteflies (Bemisia tabaci) to dicotyledonous plants. Most begomoviruses have bipartite genomes consisting of two ssDNA molecules of approximately $2.6 \mathrm{~kb}$, referred to as DNA-A and DNA-B, which are responsible for different functions in the infection process. DNA-A encodes genes responsible for viral replication (rep and ren), regulation of gene expression (trap) and particle encapsidation $(c p)$. DNA B encodes for two proteins, MP and NSP, involved in cell-to-cell movement within the plant, host range and symptom modulation [17]. The two DNA components of a given begomovirus have little sequence identity, except for a common region (CR) of approximately 200 nucleotides. This region contains the origin of replication and cis-acting elements recognized by the Rep protein $[2,15]$.

In the last two decades the incidence and severity of diseases caused by geminiviruses has increased rapidly in many areas of the world [3, 22]. The increase on the incidence of begomoviruses is specifically associated with the explosion of Bemisia populations [22].

In Brazil, the occurrence of six whitefly-transmitted begomoviruses in tomato, including Tomato golden mosaic virus (TGMV), was first reported in 1975 in the state of São Paulo [19]. Despite this report, the occurrence of begomoviruses in tomato had been of little economical relevance until recently. In the last seven years, a sharp increase in the incidence of begomovirus diseases has been observed in tomato fields in the states of Minas Gerais, São Paulo, Bahia, Pernambuco, and in the Federal District, with yield losses ranging from 40 to $100 \%$ [12, 24]. The spread of these viruses has been associated to the introduction and rapid dissemination of the B biotype of Bemisia tabaci $[16,24]$. Begomoviruses are currently the main limiting factor to tomato production in many areas of Brazil. However, characterization of these new viruses had not been carried out so far. These studies are essential if a control strategy based on host resistance is to be attempted.

The purpose of this investigation was to establish the identity and genetic diversity among begomoviruses associated with the recent disease outbreaks in tomato fields throughout Brazil. A preliminary report has been published [24].

\section{Methods}

\section{Collection of plant samples}

Tomato (Lycopersicon esculentum) plants showing begomovirus-like symptoms such as chlorosis, yellow or golden mosaic, mottling, leaf curling and distortion, were collected in fields located in several states of Brazil, from 1994 to 1999 (Table 1, Fig. 1). Fields located in the Northeastern states consisted predominantly of processing tomatoes, while those located in the Southeast were predominantly for fresh market fruits. Individual leaf samples were 
Table 1. Locations where tomato samples were obtained, dates of collection and designation of viral clones

\begin{tabular}{lll}
\hline Locationa $^{a}$ & Date of collection & Clone \\
\hline Brasília, DF & 1994 & DF-Br1 \\
Bicas, MG & 1999 & MG-Bi1 \\
Igarapé, MG & 1996 & MG-Igl \\
Igarapé, MG & 1999 & MG-Ig2 \\
Uberlândia, MG & 1996 & MG-Ub1 \\
São Fidélis, RJ & 1999 & RJ-Sf1 \\
Juazeiro, BA & 1999 & BA-Ju1 \\
Juazeiro, BA & 1999 & BA-Ju2 \\
Seabra, BA & 1996 & BA-Se1 \\
Campina Grande, PB & 1999 & PB-Cgl \\
Campina Grande, PB & 1999 & PB-Cg2 \\
Campina Grande, PB & 1999 & PB-Cg3 \\
Belmonte, PE & 1998 & PE-Be1 \\
Pesqueira, PE & 1998 & PE-Pq1 \\
Pesqueira, PE & 1997 & PE-Pq2 \\
Pesqueira, PE & 1997 & PE-Pq3 \\
Petrolina, PE & 1997 & PE-Pt1 \\
Petrolina, PE & 1997 & PE-Pt2 \\
Petrolina, PE & 1997 & PE-Pt3 \\
Petrolina, PE & 1998 & PE-Pt4 \\
Petrolina, PE & 1999 & PE-Pt5 \\
Petrolina, PE & 1999 & PE-Pt6 \\
Petrolina, PE & 1999 & PE-Pt7 \\
Mossoró, RN & 1999 & RN-Mo1 \\
\hline & & \\
\hline
\end{tabular}

${ }^{\text {a }} D F$, Federal District; $M G$, Minas Gerais; $R J$, Rio de Janeiro; $B A$, Bahia; $P B$, Paraíba; $P E$, Pernambuco; and $R N$, Rio Grande do Norte

${ }^{\mathrm{b}}$ Clones PE-Pq2 and PE-Pq 3 were obtained from the same plant sample

${ }^{\mathrm{c}}$ Clones PE-Pt1, PE-Pt2 and PE-Pt3 were obtained from the same plant sample

allowed to dry at room temperature pressed between sheets of paper towel, and stored at $-80^{\circ} \mathrm{C}$.

\section{DNA extraction, hybridization and PCR}

Total DNA was extracted from leaf samples following the procedure described by Dellaporta et al. [10]. DNA pellets were resuspended in water and stored at $-20^{\circ} \mathrm{C}$.

Two $\mu \mathrm{l}$ of total DNA were spotted onto nylon membranes (Hybond $\mathrm{N}+$ ). For some samples, $1 \mathrm{~cm}$ leaf disks were directly ground onto the membranes. Membranes were hybridized with the full-length A components of Bean golden mosaic virus (BGMV), Bean golden yellow mosaic virus (BGYMV), Tomato leaf crumple virus (ToLCrV) or Tomato mottle virus (ToMoV), labeled with ${ }^{32} \mathrm{PdCTP}$ by random priming. Hybridizations were carried out at medium stringency $\left(55^{\circ} \mathrm{C}\right)$ following standard protocols [27]. 


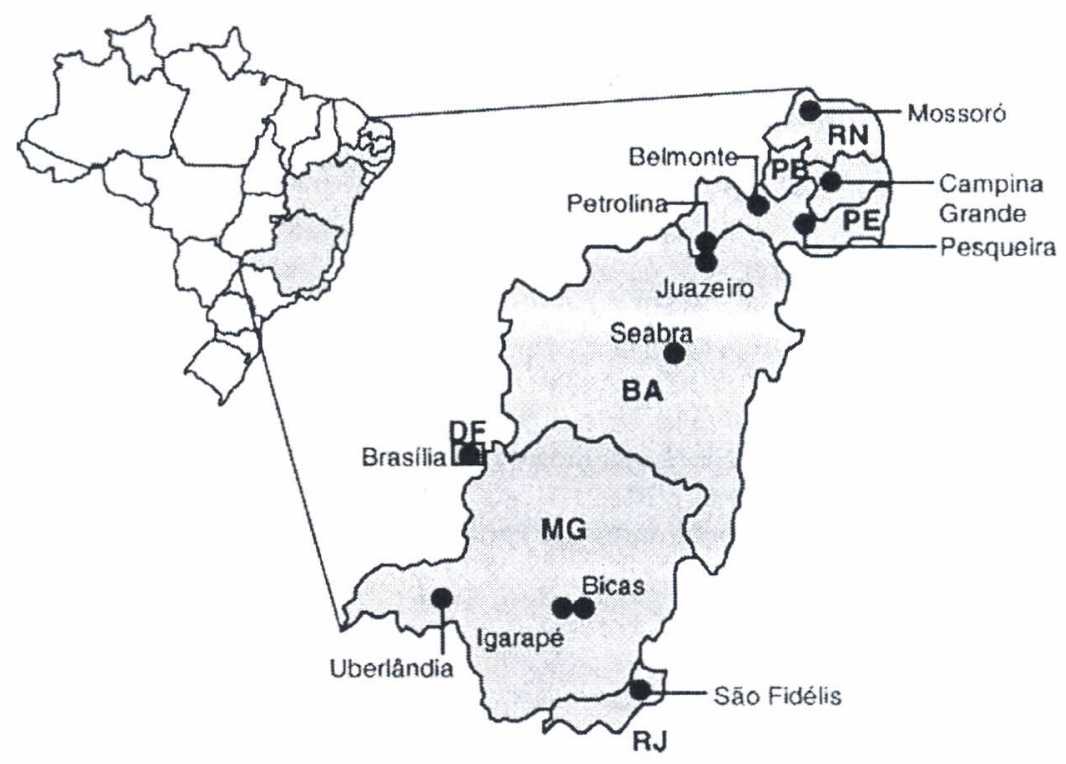

Fig. 1. Geographical map of Brazil indicating the locations where tomato samples were collected. $D F$, Federal District; $S P$, São Paulo; $M G$, Minas Gerais; $R J$, Rio de Janeiro; $B A$, Bahia; $P B$, Paraíba; $P E$, Pernambuco; $R N$, Rio Grande do Norte

Viral DNA was amplified using primer pairs PAL1v1978/PAR1c715, PAL1v1978/ PAR1c496 or PAL1v1978/CP2 [18, 25]. These primer pairs direct the amplification of a fragment of the DNA-A of begomoviruses comprising the $5^{\prime}$-region of the rep gene, the entire common region $(\mathrm{CR})$ and the $5^{\prime}$-region or the entire $c p$ gene. PCR conditions were as described by Rojas et al. [25]. Amplified fragments were visualized in agarose gels stained with ethidium bromide.

\section{Cloning and sequence analysis}

PCR-amplified products were either eluted from agarose gels using the GeneClean kit or ethanol-precipitated directly from the PCR reactions, and ligated into the pGEM-T, pGEM$\mathrm{T}$ easy or pCR-script plasmid vectors. One to five clones harboring the expected size inserts for each PCR product were selected for sequencing. Selected clones were completely sequenced in automated ABI sequencers models 310 or 377 using dye terminator cycle sequencing.

Sequences were assembled using the software package from the Genetics Computer Group, Inc. [11]. Multiple sequence alignments of nucleotide sequences of the entire cloned fragments as well as of nucleotide and derived amino acid sequences of the $\mathrm{N}$-terminal regions of the Rep and CP proteins were performed with the DNAMAN software package version 4.0 for Windows (Lynnon BioSoft, Quebec, Canada) and Clustal W (www.ebi.ac.uk/clustalw). Phylogenetic trees were generated with the MEGA program (www.megasoftware.net), using UPGMA for nucleotide sequences and neighbor-joining with Poisson correction for amino acid sequences. Tree branches were bootstrapped with 2000 replications [14]. The determination of putative recombination events was carried out using the GENECONV program [21]. The program was applied to multiple sequence alignments generated by Clustal W, using 
the command line "geneconv 〈alignment_file_name $/ \mathrm{n} 0 / \mathrm{mkg} 0.05 / \mathrm{gl}$ ", where $/ \mathrm{n} 0$ means to suppress the calculation of permutation-test $P$ values, $/ \mathrm{mkg} 0.05$ means to list all fragments whose BLAST-like $P$ value is $\leq 0.05$, and $/ g 1$ means to set $g$ scalc $=1$. The following begomovirus sequences were used in the phylogenetic and recombination analyses: Abutilon mosaic virus (AbMV, GenBank accession number X15983), African cassava mosaic virus (ACMV, J02057), Bean dwarf mosaic virus (BDMV, M88179), Bean golden mosaic virus (BGMV, M88686), Bean golden yellow mosaic virus (BGYMV, M10070), Leonurus mosaic virus (LeMV, U92532), Pepper huasteco virus (PHV, X70418), Potato yellow mosaic virus (PYMV, D00940), Sida golden mosaic Costa Rica virus (SGMCRV, X99550), Sida golden mosaic Florida virus (SGMFV, AF049336), Squash leaf curl virus (SqLCV, M38183), Tomato golden mosaic virus (TGMV, K02029), Tomato mottle virus (ToMoV, L14460), Tomato leaf crumple virus (ToLCrV, AF101476), Tomato leaf curl virus (ToLCV, S53251), Tomato leaf curl New Delhi virus (ToLCNDV, U15016), Tomato yellow leaf curl virus (TYLCV, AF105975), Tomato yellow leaf curl Sardinia virus (TYLCSV, X61153), and Tomato yellow vein streak virus (TYVSV, U79998).

\section{Results}

Tomato samples with typical begomovirus symptoms were collected in several states of Brazil's Southeastern and Northeastern regions from 1994 to 1999 (Fig. 1). A total of 323 samples were collected, and 185 tested positive for the presence of begomoviruses. All samples that tested positive by hybridization also yielded PCR fragments of expected sizes.

The selection of samples for cloning viral fragments was based primarily on the locations where samples were collected. When more than one sample from a given location tested positive by PCR, fragments from at least two samples were cloned. For some locations with a large number of positive samples, PCR-amplified fragments were directly sequenced using the PARlc496 primer. Fragments were retained or discarded based on the identity of sequences obtained. Using these criteria, a final number of 24 clones, comprising samples from seven Brazilian states, were selected for subsequent phylogenetic analyses (Table 1). In two cases, different sequences were obtained from clones from the same plant sample (Table 1), indicating the occurrence of mixed infections in the field. Analyses were carried out using a $1152 \mathrm{nt}$ fragment, from which an N-terminal sequence of the Rep protein with 221 amino acids, and an Nterminal sequence of the capsid protein with $47 \mathrm{aa}$, were deduced. The fragment also included the entire intergenic region of the DNA-A, including the origin of replication.

The sequences of the intergenic regions from all 24 clones were aligned using Clustal W (data not shown). This region contains a series of cis-acting elements involved in DNA replication and transcription of the rep gene [1]. All such elements are present in the sequences of the 24 tomato begomovirus clones, including (i) an inverted repeat and two direct repeats (binding sites for the Rep protein), (ii) the TATA box for the rep gene, and (iii) a conserved stem-loop motif which includes the nonanucleotide sequence nicked by the Rep protein to initiate DNA replication. Although the sequences of the inverted and direct repeats 
show significant variation among the clones, the stem-loop and the nonanucleotide sequences are completely conserved.

The nucleotide sequence identities for the $1152 \mathrm{nt}$ fragments from all 24 clones ranged from 66 to $100 \%$ (sequence identity tables can be examined at 〈www.ufv.br/dfp/virologia/gemini/tables.html)). Similar values were obtained when only the CP amino acid sequence, which has been used to establish taxonomical relationships among begomoviruses $[5,20,26]$, was analyzed. When the $1152 \mathrm{nt}$ fragment was submitted to a BLAST search, identity values were always below $80 \%$, except for clone MG-Bil (85\% identical to BGMV) (data not shown). When the $\mathrm{CP}$ sequences of the 24 tomato begomovirus clones were submitted to a BLAST search, identities were always below $90 \%$, except for clones MG-Ig2 (95\% identical to LeMV), and MG-Bil (93\% identical to BGMV) (data not shown). Phylogenetic trees were prepared based on the nt sequence of the entire fragment, or the aa sequence of the CP (Fig. 2).

When the entire fragment was analyzed, clones DF-Br1 and PE-Pq3 were less than $82 \%$ identical to all other tomato clones, as well as to previously characterized species. Similar values were found when their Rep or CP aa sequences were used for the analyses. Moreover, these two clones were placed in distinct branches in both phylogenetic trees (Fig. 2). These results suggest that these two clones represent two distinct, new begomovirus species.

A third new species is represented by clones PE-Be1, PE-Pq1, PE-Pt4, RJSf1, BA-Ju2, BA-Se1 and MG-Ig1. The complete DNA-A nucleotide sequences of clones BA-Se1 and MG-Ig1 have been determined (GenBank accession numbers AF490004 and AY049206, respectively), and the name Tomato chlorotic mottle virus (ToCMV) is proposed for this species. Phylogenetic analysis revealed three subgroups of ToCMV isolates (Fig. 2). The first is comprised of clones PEBe1, PE-Pq1 and PE-Pt4 (which are 99.9\% identical to each other in terms of sequence). The second is comprised of clones RJ-Sf1 and BA-Ju2, with nt sequence identities ranging from 82 to $90 \%$ for the entire fragment. The third subgroup is comprised of clones MG-Ig1 and BA-Se1. These two clones are closely related to each other, with nt sequence identities greater than $89 \%$ for either their entire fragments or their Rep, CR and CP regions. The nt sequences of these clones, and the aa sequences of their CP's, are 84-86\% and $85-89 \%$ identical, respectively, to the other five clones representing ToCMV. However, their Rep and CR sequences are only $80-86 \%$ and $77-78 \%$ identical at the aa and nt levels, respectively, to those clones. The GENECONV program failed to detect potential recombination events between these clones. Therefore, although these seven clones are certainly related based both on nucleotide sequence comparisons and phylogenetic analysis, it is difficult to conclude, based solely on these analyses, whether they actually comprise a single species or should be further subdivided into distinct species. Infectious clones of isolates BA-Sel and MG-Ig1 have been obtained (S. G. Ribeiro, E. C. Andrade and F. M. Zerbini, manuscript in preparation), and further genetic studies using these clones should clarify their taxonomical relationships. 


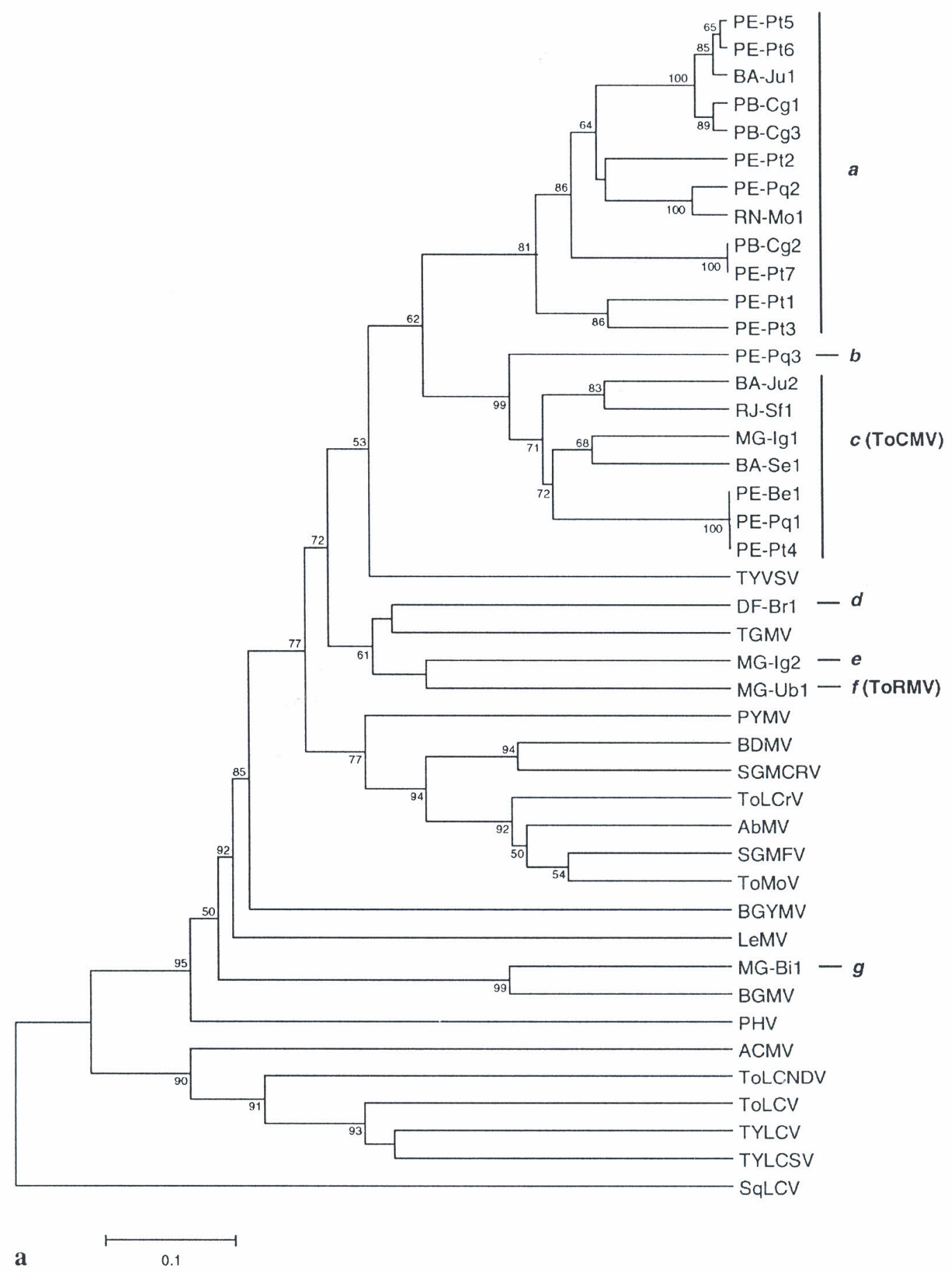

Fig. 2 (continued) 


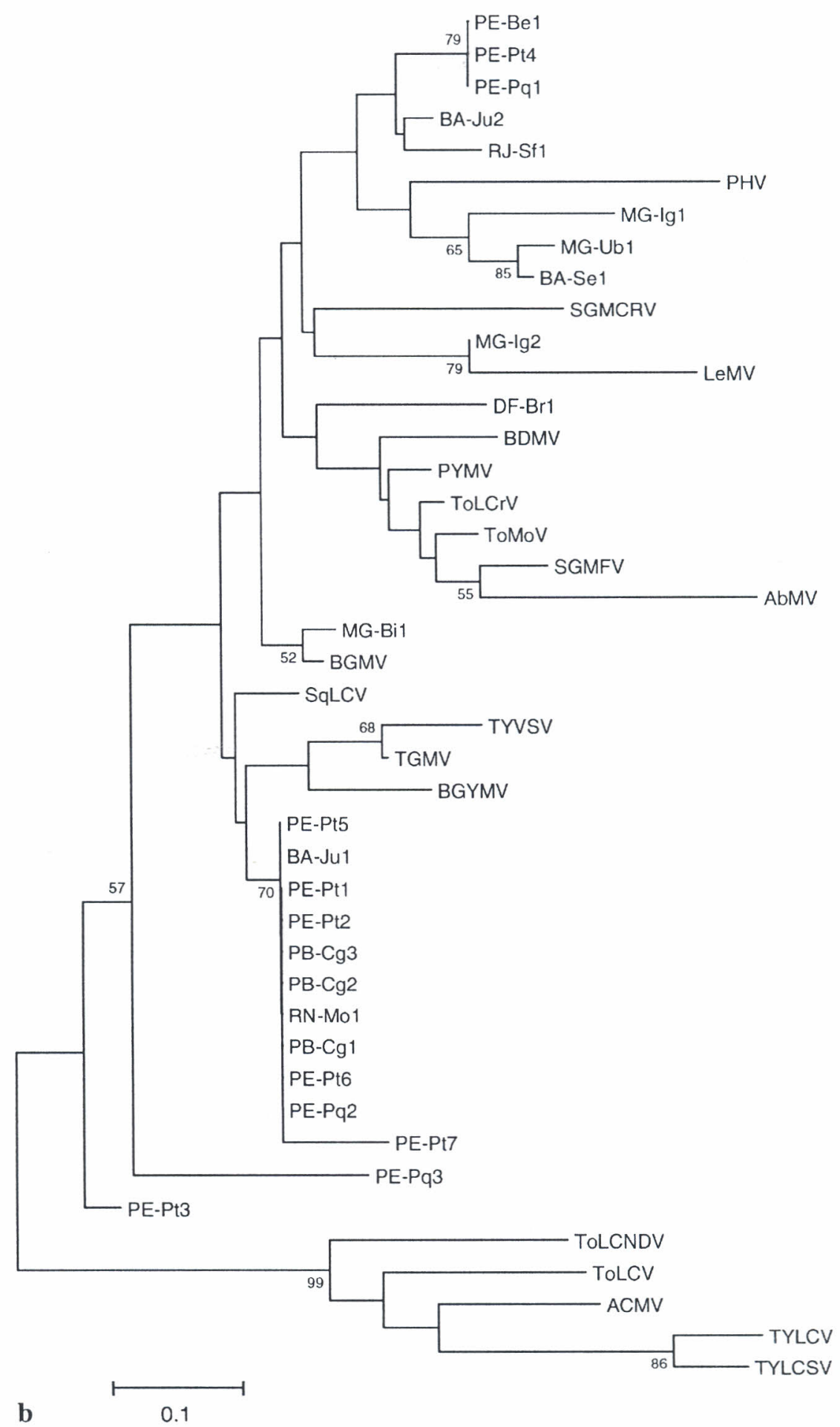


A fourth new species is represented by clones BA-Ju1, PB-Cg1, PB-Cg2, PBCg3, PE-Pq2, PE-Pt1, PE-Pt2, PE-Pt3, PE-Pt5, PE-Pt6, PE-Pt7, and RN-Mo1. Identities between any two of these clones are never below $87 \%$ for the entire fragment (nt) or $83 \%$ for the CP (aa). These clones were also placed in the same branch of both phylogenetic trees, although the genetic distances were higher in the tree based on the entire fragment when compared to the CP tree (Fig. 2). Within the clones that represent this species, three clusters of highly identical clones can be identified: clones PB-Cg2 and PE-Pt7 are 100\% identical, clones PE-Pq2 and RN-Mo1 are 97\% identical, and clones BA-Ju1, PB-Cg1, PB-Cg3, PE-Pt5 and PE-Pt6 are at least $95 \%$ identical to each other. Clones PE-Pt1, PEPt2 and PE-Pt3 were obtained from the same plant sample. When the Rep, RC and $\mathrm{CP}$ regions of these clones are compared separately, it is clear that clones PE-Pt1 and PE-Pt3 share the same Rep and CR ( $99 \%$ identity in both cases, aa for Rep and nt for CR), while clones PE-Pt1 and PE-Pt2 share the same CP ( $100 \%$ aa identity). Therefore, clone PE-Pt 1 seems to be a recombinant between PE-Pt2 and PE-Pt3. This hypothesis was reinforced by gene conversion analysis using the GENECONV program, which detected potential recombination events between these clones (the output from the GENECONV analysis can be found at $\langle$ www.ufv.br/dfp/virologia/gemini/geneconv_res.html $\rangle$ ). In fact, when the Rep, $\mathrm{CR}$ and $\mathrm{CP}$ regions of all clones representing this fourth species are compared separately, a complex picture of distinct Rep/CR and CP sequences arises (Fig. 3a). All clones, except PE-Pt3, share the same type of CP. However, five distinct types of Rep/CR sequences can be identified. The nt sequence identity between these distinct types of Rep/CR sequences can be as low as 61\% (Fig. 3b), suggesting that trans-replication may not occur between such viruses. In agreement with the results of sequence comparisons, clones $\mathrm{PB}-\mathrm{Cg} 2$ and $\mathrm{PE}-\mathrm{Pt} 7$ have the same types of Rep/CR and CP sequences. The same is true for clones PE-Pq2 and RN-Mo1, and for clones BA-Ju1, PB-Cg1, PB-Cg3, PE-Pt5 and PE-Pt6. Together, these results indicate that this species comprises a number of distinct strains, which probably originated via recombination between distinct, unidentified parent viruses.

The nt sequence identity for the entire fragment of clone MG-Ub1 was always below $80 \%$ with all other tomato clones or previously characterized species. However, its CP is $96 \%$ identical (aa) to the one from clone BA-Se1. Clone MG-Ubl was placed in the same branch of clone BA-Sel in the tree based on the $\mathrm{CP}$ sequence (Fig. 2b). However, these two clones were placed in completely distinct branches of the tree based on the sequence of entire fragment

Fig. 2. Phylogenetic trees constructed based on the nucleotide sequence of the entire fragment sequenced (a), or the deduced 47 amino acid sequence of the capsid protein (b). Trees were generated with the MEGA program (www.megasoftware.net), using UPGMA for nucleotide sequences and neighbor-joining with Poisson correction for amino acid sequences. Tree branches were bootstrapped with 2000 replications. The scale bar represents Nei's genetic distance. The seven new begomovirus species proposed are indicated to the right of tree based on the entire fragment 
(a)

$$
\text { Rep/CR CP }
$$

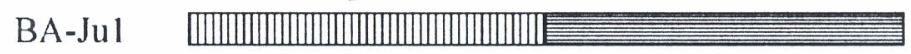

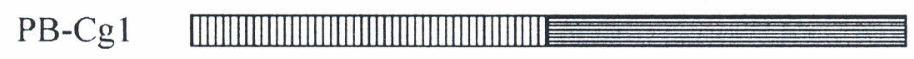

PB-Cg3

PE-Pt5

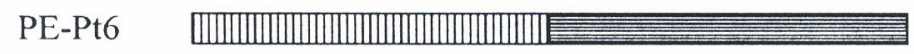

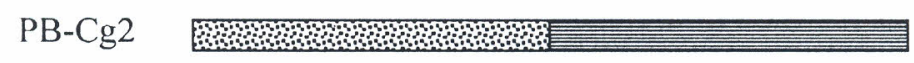

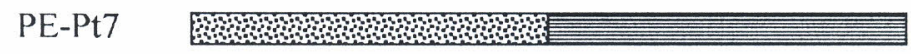

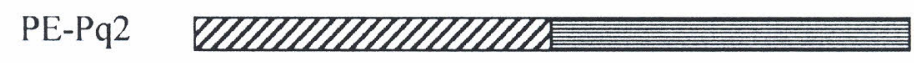

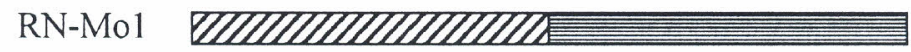

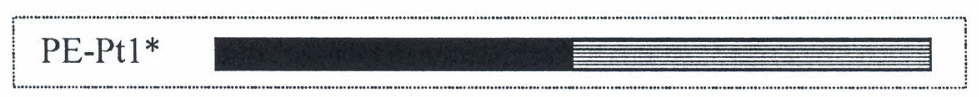

PE-Pt2*

PE-Pt3* $\square$

(b)

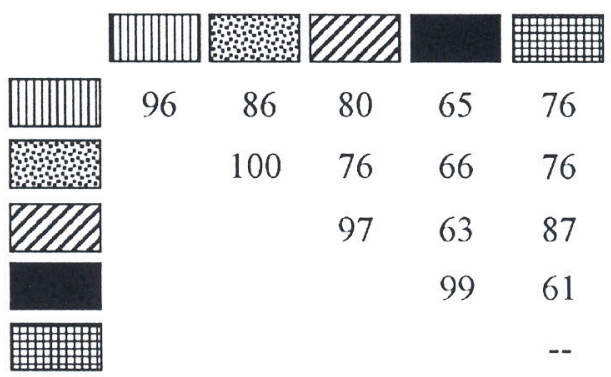

Fig. 3. a Schematic representation of the Rep/CR and CP regions from the 12 related isolates represented by clone BA-Jul. Each type of Rep/CR and CP sequence is indicated by a distinct pattern: five patterns for $\mathrm{Rep} / \mathrm{Cr}$ and two patterns for the CP. Clones marked with an asterisk were obtained from the same plant sample. The putative recombinant isolate PE-Pt1, which shares the same Rep/CR with isolate PE-Pt3 and the same CP with isolate PE-Pt2, is indicated by the dotted box. $\mathbf{b}$ Average nucleotide sequence identities between the five distinct types of $\mathrm{Rep} / \mathrm{CR}$ regions

(Fig. 2a). The possibility of MG-Ub1 being a recombinant was tested with the GENECONV program. However, this analysis failed to identify potential recombination events between MG-Ub1 and BA-Se1, or with any other clone or previously 
characterized species. Thus, clone MG-Ub1 represents a fifth new species. This clone has been completely sequenced (GenBank accession numbers AF291075 and AF291706), and the name Tomato rugose mosaic virus (ToRMV) is proposed.

The nt sequence of the entire fragment from clone MG-Bil is $85 \%$ identical to BGMV. The Rep and CP proteins from these viruses share 82 and $94 \%$ identity (aa), respectively, and their CRs are $77 \%$ identical (nt). Clone MG-Bil was placed in the same branch of BGMV in both trees (Fig. 2). However, since they have distinct host ranges (BGMV does not infect tomatoes) and probably do not transreplicate, BGMV and MG-Bil are probably better considered to be distinct, albeit related, species. Similarly, the nucleotide sequence of clone MG-Ig2 is 74\% identical to LeMV, and their Rep and CP proteins share 66 and 95\% identity, respectively. Clone MG-Ig2 was placed in the same branch of LeMV in the CP tree, but in distinct branches in the tree based on the entire fragment. Since LeMV does not infect tomatoes (J. C. Faria, personal communication) and the two viruses probably do not trans-replicate, clone MG-Ig2 might also represent a distinct, new species.

Together, our results confirm the widespread occurrence of tomato-infecting begomoviruses in Brazil, and indicate the existence of at least seven new begomovirus species in the country.

\section{Discussion}

Begomoviruses have been present in Brazil for a long time, although they were not recognized as a distinct group of plant viruses until the 1970's. Reports of whitefly-transmitted viral diseases of Abutilon and other species of the Malvaceae date as far back as the 1950's [6, 7]. Bean golden mosaic virus (BGMV) was first described in Brazil in the 1960's [8]. The incidence of BGMV increased dramatically in Brazil during the 1970's, due to the increasing acreage occupied by soybeans, an excellent host of the whitefly [9]. The first report of tomatoinfecting begomoviruses in Brazil (including TGMV) appeared at this time [19]. Interestingly, tomato-infecting begomoviruses did not become an economical problem in the country, most likely because the A biotype of Bemisia tabaci, which was prevalent at the time, does not normally colonize tomatoes. The B biotype of $B$. tabaci, which readily colonizes tomato plants [4], was observed in Brazil for the first time in 1994, and quickly disseminated throughout the warm and dry areas of the country [16].

The emergence of tomato-infecting begomoviruses in Brazil displayed a remarkable correlation to the introduction and dissemination of the B biotype of B. tabaci throughout the country. A preliminary sequence analysis of PCR fragments from these viruses indicated that they represented several new begomovirus species [24], suggesting that the vector was transferring indigenous viruses from weed and/or wild hosts into the tomato.

Although symptoms like yellow or golden mosaic, leaf crumpling, epinasty, down cupping, and dwarfing were commonly associated with begomovirus infection, it was difficult to establish a precise relationship between a particular type of symptom and a given viral species. Symptoms are highly dependent on the 
host genotype, environmental conditions, or the occurrence of mixed infections. Infectious clones of some of these new begomoviruses have been recently obtained (S. G. Ribeiro, E. C. Andrade, J. J. Fernandes and F. M. Zerbini, unpublished results), which should allow for a better correlation between viral species and symptoms to be determined. However, this correlation might be of little practical use, since mixed infections will continue to occur in the field. In view of these facts, our approach to viral characterization was based mainly on molecular data.

Detailed analysis of the sequences of all 24 clones demonstrates the existence of previously undescribed begomovirus species infecting tomatoes in Brazil. At least seven putative new species were identified. Phylogenetic analysis placed these viruses in distinct clades, apart from all the previously characterized New World begomoviruses, but more closely related to begomoviruses from Brazil (TYVSV, TGMV and BGMV). This suggests that these viruses are indigenous to Brazil, and have not been introduced from other regions. A likely scenario for such rapid emergence would be the transferring of these viruses from local wild hosts to tomatoes, followed by rapid adaptation to the new host via recombination or pseudorecombination. The new viruses are then disseminated by the insect vector or due to the movement of infected transplants. Detection of ToCMV in Belmonte (PE), Igarapé (MG), Juazeiro (BA), Pesqueira (PE), Petrolina (PE), São Fidélis (RJ) and Seabra (BA), which are up to $2000 \mathrm{~km}$ apart (Fig. 1), suggests that dissemination of these viruses within the country is rapidly taking place. Alternatively, the fact that samples infected by ToCMV were collected at both Igarapé and Seabra in 1996 (Table 1) suggests that the same virus could have emerged simultaneously in these regions.

The analysis of the 12 related clones BA-Ju1, PB-Cg1, PB-Cg2, PB-Cg3, PEPq2, PE-Pt1, PE-Pt2, PE-Pt3, PE-Pt5, PE-Pt6, PE-Pt7 and RN-Mol illustrates the hypothesis that new begomoviruses evolve by recombination or pseudorecombination between previously existing species $[21,26,28,30]$. Comparisons between distinct regions of the amplified DNA-A fragments present a strong indication that clone PE-Pt1 is a recombinant between PE-Pt2 and PE-Pt3: it contains the CP sequence of PE-Pt2 and the Rep/CR sequence of PE-Pt3. The fact that these three clones were obtained from the same plant sample further supports this hypothesis. There are several well-documented cases of recombination among begomoviruses, in many cases leading to the emergence of more virulent or better-adapted viruses in specific host plants. Such is the case of Pepper huasteco virus in Mexico, which is a recombinant between a "New World" and an "Old World" begomovirus [28]. Also, an unusually virulent isolate of African cassava mosaic virus (ACMV) from Uganda was shown to be a recombinant between ACMV and Eastern African cassava mosaic virus (EACMV) [30].

A different perspective on the genetic diversity of tomato-infecting begomoviruses in Brazil is the existence of at least four distinct species in the state of Minas Gerais, and three distinct species in the state of Pernambuco. Three distinct species were found in Bicas and Igarapé (MG), located less than $30 \mathrm{~km}$ apart from each other. Two distinct species were found in Petrolina (PE), and also in Pesqueira (PE). All of these cities are located in major tomato-growing areas. 
The fact that distinct viruses were detected at such close proximity is further evidence of the simultaneous transfer of pre-existing indigenous viruses from wild hosts into tomatoes.

It is possible that, as these new viruses adapt to their new host, one or two viral species will start to predominate and, in the medium to long term, will displace less adapted species, similar to the situation that has been occurring in Mexico over the last two decades [22]. Several begomoviruses were described in that country over this period of time. Over the years, the incidence of some viruses, such as ToLCrV, has been reported to have decreased, accompanied by a simultaneous increase in the incidence of other species, such as PHV $[22,29]$. The realization that such scenario could be taking place in Brazil is of great importance if a management strategy based on host resistance is to be attempted to control these viruses. Unless a source of resistance with a broad spectrum is identified, the identification of species-specific resistance genes might lead to a quick breakdown of resistance, due to the frequent emergence of new species and the displacement of species less adapted to tomato by fitter ones. It is interesting to note the contrast between the high degree of genetic variability of tomato-infecting begomoviruses in Brazil with the low variability found among Phaseolus-infecting begomoviruses [13]. In this case, it would seem the virus and its host have been co-evolving for a significantly greater period of time, which probably allowed selection of better adapted viruses to predominate in the field, resulting in lower genetic diversity.

The introduction of the B biotype of Bemisia tabaci and the subsequent emergence of tomato-infecting begomoviruses in Brazil has resulted in increased cost of tomato production as well as additional environmental costs due to pollution by increased insecticide use. Clearly, management strategies based on host resistance would be highly preferable. However, these can only be successfully implemented if the complex diversity and evolutionary aspects of the viruses involved is fully recognized.

\section{Acknowledgements}

The authors wish to thank Leonardo Boiteux, Iedo V. Carrijo, Severino H. Lima, Arildo M. Rego, Luciane V. Rezende, and Silvaldo F. Silveira for assistance in collecting samples, Josias C. Faria and Robert L. Gilbertson for providing begomovirus clones used as probes, Eliane A. Gomes for assistance in automated sequencing, Daniel J. Rigden for help using the GENECONV program, Robert L. Gilbertson, Elizabeth P. B. Fontes and Renato O. Resende for helpful discussions, and Marcel Prins and Ed Rybicki for critical review of the manuscript.

\section{References}

1. Arguelo-Astorga G, Guevara-González RG, Herrera-Estrela L, Rivera-Bustamante R (1994) Geminivirus replication origins have a group-specific organization of iterative elements: a model for replication. Virology 203: 90-100

2. Arguelo-Astorga G, Herrera-Estrela L, Rivera-Bustamante R (1994) Experimental and theoretical definition of geminivirus origin of replication. Plant Mol Biol 26: $553-556$ 
3. Brown JK, Bird J (1992) Whitefly-transmitted geminiviruses and associated disorders in the Americas and the Caribbean basin. Plant Dis 76: 220-225

4. Brown JK, Frohlich DR, Rosell RC (1995) The sweetpotato or silverleaf whiteflies: Biotypes of Bemisia tabaci or a species complex? Annu Rev Entomol 40: 511-534

5. Brown JK, Idris AM, Torres-Jerez I, Banks GK, Wyatt SD (2001) The core region of the coat protein gene is highly useful for establishing the provisional identification and classification of begomoviruses. Arch Virol 146: 1581-1598

6. Costa AS, Bennett CW (1950) Whitefly transmitted mosaic of Euphorbia prunifolia. Phytopathology 40: 266-283

7. Costa AS (1955) Studies on Abutilon mosaic in Brazil. Phytopathol Z 24: 97-112

8. Costa AS (1965) Three whitefly-transmitted virus diseases of beans in São Paulo, Brazil. Plant Prot Bull F.A.O. 13: 2-12

9. Costa AS (1975) Increase in the populational density of Bemisia tabaci, a threat to widespread virus infection of legume crops in Brazil. In: Bird J, Maramorosch K (eds) Tropical diseases of legumes. Academic Press, New York, pp 171

10. Dellaporta SL, Wood J, Hicks JB (1983) A plant DNA minipreparation: Version II. Plant Mol Biol Rep 1: 19-21

11. Devereux J, Haeberli P, Smithies O (1984) A comprehensive set of sequence analysis programs for the VAX. Nucleic Acids Res 12: 387-395

12. Faria JC, Souza-Dias JAC, Slack S, Maxwell DP (1997) A new geminivirus associated with tomato in the State of São Paulo, Brazil. Plant Dis 81: 423

13. Faria JC, Maxwell DP (1999) Variability in geminivirus isolates associated with Phaseolus spp. in Brazil. Phytopathology 89: 262-268

14. Felsenstein J (1985) Confidence limits on phylogenies with a molecular clock. Systemat Zool 34: 783-791

15. Fontes EPB, Gladfelter HJ, Schaffer RL, Petty ITD, Hanley-Bowdoin L (1994) Geminivirus replication origins have a modular organization. Plant Cell 6: 405-416

16. França FH, Villas-Boas GL, Castelo-Branco M (1996) Ocurrence of Bemisia argentifolii Bellows \& Perring (Homoptera: Aleyrodidae) in the Federal District (in Portuguese). An Soc Entomol Brasil 25: 369-372

17. Hanley-Bowdoin L, Settlage SB, Orozco BM, Nagar S, Robertson D (1999) Geminiviruses: Models for plant DNA replication, transcription, and cell cycle regulation. Crit Rev Plant Sci 18: 71-106

18. Inoue-Nagata AK, Nagata T, Miranda JDR, Bezerra IC, Ribeiro SG, Ávila AC (1999) Expression of the coat protein of a tomato-infecting geminivirus in Escherichia coli for serological studies. Virus Rev Res 4: 151

19. Matyis JC, Silva DM, Oliveira AR, Costa AS (1975) Purification and morphology of tomato golden mosaic virus (in Portuguese). Summa Phytopathol 1: 267-275

20. Padidam M, Beachy RN, Fauquet CM (1995) Classification and identification of geminiviruses using sequence comparisons. J Gen Virol 76: 249-263

21. Padidam M, Sawyer S, Fauquet CM (1999) Possible emergence of new geminiviruses by frequent recombination. Virology 265: 218-224

22. Polston JE, Anderson PK (1997) The emergence of whitefly-trasmitted geminiviruses in tomato in the western hemisphere. Plant Dis 81: 1358-1369

23. Pringle CR (1999) Virus taxonomy, 1999. Arch Virol 144: 2065-2070

24. Ribeiro SG, Ávila AC, Bezerra IC, Fernandes JJ, Faria JC, Lima MF, Gilbertson RL, Zambolim EM, Zerbini FM (1998) Widespread occurrence of tomato geminiviruses in Brazil, associated with the new biotype of the whitefly vector. Plant Dis 82: 830 
25. Rojas MR, Gilbertson RL, Russell DR, Maxwell DP (1993) Use of degenerate primers in the polymerase chain reaction to detect whitefly-transmitted geminiviruses. Plant Dis 77: $340-347$

26. Rybicki EP (1994) A phylogenetic and evolutionary justification for three genera of Geminiviridae. Arch Virol 139: 49-77

27. Sambrook J, Fritsch EF, Maniatis T (1989) Molecular cloning - A laboratory manual, 2. edn. Cold Spring Harbor Laboratory Press, Cold Spring Harbor, NY

28. Torres-Pacheco I, Garzón-Tiznado JA, Herrera-Estrela L, Rivera-Bustamante RF (1993) Complete nucleotide sequence of pepper huasteco virus: Analysis and comparison with bipartite geminiviruses. J Gen Virol 74: 2225-2231

29. Torres-Pacheco I, Garzón-Tiznado JA, Brown JK, Becerra-Flora A, Rivera-Bustamante $\mathrm{R}$ (1996) Detection and distribution of geminiviruses in Mexico and the Southern United States. Phytopathology 86: 1186-1192

30. Zhou X, Liu Y, Calvert L, Munoz C, Otim-Nape GW, Robinson DJ, Harrison BD (1997) Evidence that DNA-A of a geminivirus associated with severe cassava mosaic disease in Uganda has arisen by interspecific recombination. J Gen Virol 78: 2101-2111

Author's address: Dr. F. Murilo Zerbini, Departamento de Fitopatologia/BIOAGRO, Universidade Federal de Viçosa, Viçosa, MG, Brazil 36571-000; e-mail: zerbini@ufv.br 